\title{
Implementasi Multi Factor Evaluation Process (MFEP) untuk Pemilihan Kompetensi Keahlian Calon Siswa SMK Ketintang Surabaya
}

\author{
Lukman Junaedi, Ahmad Shidiq Cahyono, Achmad Muchayan \\ Sistem Informasi, Fakultas Ilmu Komputer, Universitas Narotama Surabaya, \\ Jl. Arif Rahman Hakim No. 51, Surabaya 60117, Indonesia \\ lukman.junaedi@narotama.ac.id
}

\begin{abstract}
Abstrak
Dalam dunia pendidikan menengah atas kejuruan (SMK), banyak sekali kompetensi keahlian yang tersedia di masing-masing Sekolah. SMK Ketintang Surabaya merupakan institusi bidang pendidikan yang melayani 5 (lima) kompetensi keahlian yaitu Akuntansi dan Keuangan Lembaga (AKL), Otomatisasi dan Tata Kelola Perkantoran (OTKP), Bisnis Daring dan Pemasaran (BDP), Teknik Komputer dan Jaringan (TKJ), dan Multimedia (MM). Dalam menentukan peminatan di kompetensi keahlian, masih banyak siswa merasa salah dalam memilih kompetensi keahlian sehingga timbul fenomena tinggal kelas dan pindah sekolah atau kompetensi keahlian yang meningkat. Metode Multi Factor Evaluation Process (MFEP) merupakan salah satu metode Sistem Pendukung Keputusan (SPK) dengan menimbang berbagai kriteria yang mempengaruhi alternatif. Calon siswa dapat memilih kompetensi keahlian sesuai dengan minatnya dengan bantuan dari progam SPK berbasis web. Hasil dari artikel ini menjelaskan tentang progam SPK yangt menampilkan diagram peminatan yang dipilih calon siswa sehingga calon siswa tidak merasa salah dalam pemilihan kompetensi keahlian. Calon siswa dapat memilih kompetensi keahlian yang sesuai minatnya dan tidak menjadi siswa yang salah memilih kompetensi keahlian dengan presentase $54,4 \%$.
\end{abstract}

Kata kunci: SPK, MFEP, SMK, Kompetensi Keahlian

\section{Pendahuluan}

Satu dari banyak jenjang pendidikan di Indonesia adalah Sekolah Menengah Kejuruan (SMK). Pada jenjang SMK ada beberapa kompetensi keahlian yang dapat dipilih oleh siswa. Menurut Peraturan Direktur Jendral Pendidikan Dasar dan Menengah Nomor 06/D.D5/KK/2018 tertanggal 7 Juni 2018 tentang Spektrum Keahlian Sekolah Menengah Kejuruan (SMK) atau Madrasah Aliyah Kejuruan (MAK), telah menetapkan jumlah kompetensi keahlian yang dapat dipilih sebanyak 142 kompetensi keahlian yang terdiri dari 49 Progam Keahlian serta dibagi menjadi 9 Bidang Keahlian (Kemdikbud RI, 2018).

Salah satu pendidikan SMK yang ada di Surabaya Adalah SMK Ketintang Surabaya dengan memiliki 5 Kompetensi Keahlian yaitu Akuntansi dan Keuangan Lembaga (AKL), Otomatisasi dan Tata Kelola Perkantoran (OTKP), Bisnis Daring dan Pemasaran (BDP), Teknik Komputer dan Jaringan (TKJ), dan Multimedia (MM). Bagi calon siswa mendapatkan kesulitan dengan beberapa Kompetensi Keahlian yang ada di SMK Ketintang Surabaya. Hal ini mengakibatkan calon siswa masih merasa bingung dan tidak percaya diri dalam memilih Kompetensi Keahlian yang diinginkan. Karena tidak adanya rasa percaya diri tersebut, menurut JawaPos.com terjadi kenaikan dalam jumlah siswa yang mengalami tinggal kelas (JawaPos.com, 2017).

Analisis Multi Factor Evaluation Process (MFEP) ditujukan untuk membuat analisis beberapa faktor yang mempengaruhi dalam calon siswa dalam memilih kompetensi keahlian sesuai dengan minat dan kesuakaannya (Wahyuni, 2017). Faktor-faktor yang dapat mempengaruhi antara lain faktor 
penghasilan orang tua, faktor nilai mata pelajaran, faktor kelulusan masing-masing kompetensi keahlian, faktor penyerapan dunia kerja terhadap lulusan, faktor peminatan yang dapat dipilih calon siswa sesuai dengan minatnya. Dalam melakukan analisis tersebut dilakukan langkah-langkah seperti pengumpulan data dengan observasi, kuisioner dan studi literatur terdahulu, analisis kriteria dan sub kriteria serta pemberian nilai bobot, dan penarikan kesimpulan. Lalu peneliti membuat desain SPK yang akan dibuat mock-up sistem dalam bentuk user interface. Kemudian dilanjutkan pengkodingan sistem.

\section{Metode Penelitian}

Agar penelitian ini sesuai dengan rumusan penelitian, maka dibuat sebuat metodologi penelitian pada diagram flowchart Gambar 1 untuk memudahkan langkah-langkah pelaksanaan penelitian.

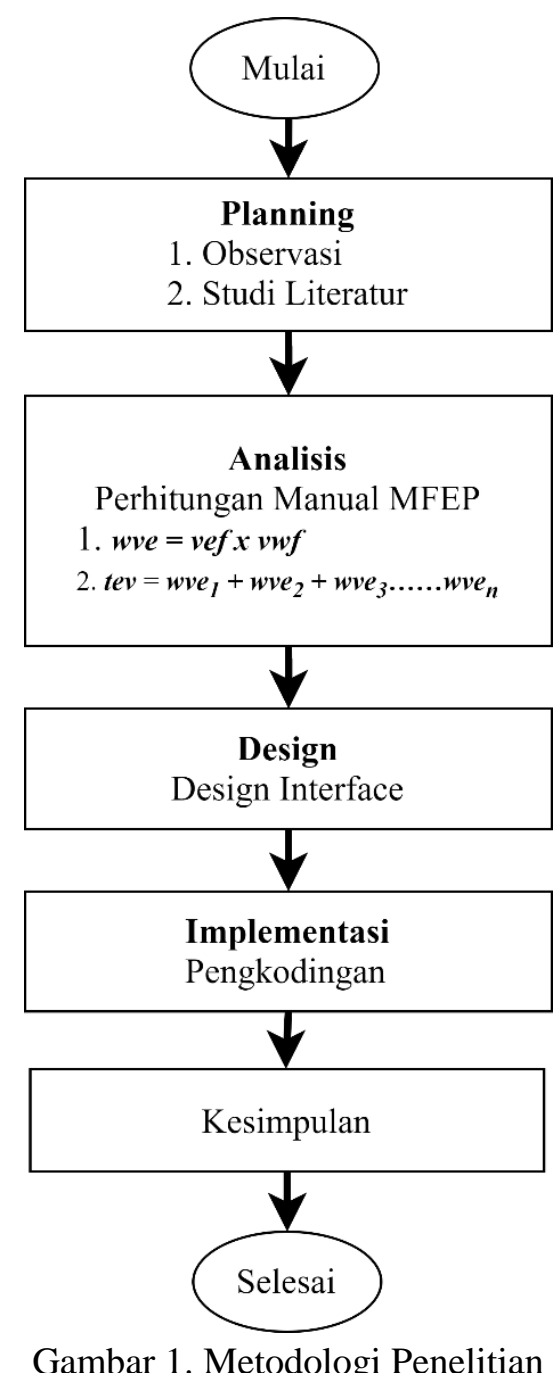

Tahapan dalam metode penelitian menggunakan metode pengembangan sistem Waterfall sebagai berikut (Manik, dkk., 2015; Wuragil, dkk., 2014):

a. Tahap Planning

Tahap pertama yaitu melakukan pengumpulan data yang dibutuhkan dalam penelitian ini dengan metode observasi dan kuisioner di SMK Ketintang Surabaya dan mempelajari literatur terdahulu sebagai pendukung penelitian ini (Muchlis, dkk., 2019). 
b. Tahap Analisis

Dilanjutkan tahap analisis dengan melakukan analisa beberapa alternatif, kriteria dan subkriteria beserta pemberian bobotnya sesuai dengan metode Multi Factor Evaluation Process (MFEP). Setelah itu melakukan perhitungan manual dari metode tersebut sehingga menemukan alternatif terbaik dari beberapa alternatif yang tersedia dengan menimbangkan beberapa faktor dari subkriteria yang dipilih (Primadasa dan Amalia, 2018; Widjaja dan Mujito, 2017).

c. Tahap Desain

Setelah pembuatan diagram, selanjutnya dibuatkan bentuk mock-up aplikasi dalam bentuk design interface yang mana akan digunakan dalam tahapan selanjutnya yaitu tahapan implementasi.

d. Tahap Implementasi

Selanjutnya melakukan pengkodingan sistem berbasis web dengan template Bootstrap 4 dan PHP 7 serta menggunakan database MySql.

e. Tahap Kesimpulan

Tahap akhir adalah menarik kesimpulan dari penelitian yang telah dilakukan yang dimulai dari planning sampai dengan pengkodingan aplikasi.

\section{Hasil dan Pembahasan}

\section{1 Perhitungan Manual MFEP}

\section{a. Analisis Alternatif dan Kriteria}

Penetuan alternatif pada SMK Ketintang Surabaya terdiri dari beberapa jurusan yang akan diuraikan pada Tabel 1. Alternatif pada progam SPK ini adalah kompetensi keahlian yang dilayani oleh SMK Ketintang Surabaya yang melayani kompetensi keahlian sebanyak 5 (lima) kompetensi keahlian.

Tabel 1. Alternatif Keputusan

\begin{tabular}{cl}
\hline No. & \multicolumn{1}{c}{ Kompetensi Keahlian } \\
\hline 1. & Akuntansi dan Keuangan Lembaga (AKL) \\
2. & Otomatisasi dan Tata Kelola Perkantoran (OTKP) \\
3. & Bisnis Daring dan Pemasaran (BDP) \\
4. & Teknik Komputer dan Jaringan (TKJ) \\
5. & Multimedia (MM) \\
\hline
\end{tabular}

Setelah menetukan alternatif keputusan selanjutnya adalah menentukan faktor-faktor yang dianggap penting dalam pengambilan keputusan yang disebut dengan kriteria. Kemudian memberikan bobot nilai pada kriteria yang digunakan harus sama dengan 1 (bobot $=1$ ) yang ditunjukan oleh Tabel 2 .

Tabel 2. Daftar dan Pembobotan Kriteria

\begin{tabular}{clc}
\hline Kode & \multicolumn{1}{c}{ Kriteria } & Bobot \\
\hline K01 & Peminatan & 0,35 \\
K02 & Penghasilan Orang Tua & 0,15 \\
K03 & Kelulusan & 0,15 \\
K04 & Penyerapan Dunia Kerja & 0,1 \\
K05 & Sarpras & 0,1 \\
K06 & Nilai Mapel & 0,15 \\
\hline & Total & 1 \\
\hline
\end{tabular}

Kriteria diatas merupakan bebarapa kriteria seperti K01 Peminatan, K02 Penghasilan Orang Tua, K03 Kelulusan, K04 Penyerapan Dunia Kerja, K05 Sarpras, dan K06 Nilai Mapel. Nilai bobot pada kriteria adalah penilaian subjektif dari keputusan bersama Ketua Kompetensi Keahlian (kakomli). 


\section{b. Analisis Sub Kriteria dan Pembobotan}

Pada tahap selanjutnya adalah melakukan pemilihan lebih detail dari kriteria yang disebut dengan subkriteria yang akan berpengariuh pada pemilihan alternatif terbaik selain kriteria itu sendiri.

Tabel 3. Daftar dan Pembobotan Kriteria

\begin{tabular}{|c|c|c|c|}
\hline Kode & Kriteria & Subkriteria & Nilai Bobot \\
\hline \multirow{4}{*}{ K01 } & \multirow{4}{*}{ Peminatan } & C3 Kompetensi Keahlian & 4 \\
\hline & & C2 Dasar Progam Keahlian & 3 \\
\hline & & C1 Dasar Bidang Keahlian & 2 \\
\hline & & C4 Muatan Lokal & 1 \\
\hline \multirow{5}{*}{ K02 } & \multirow{5}{*}{$\begin{array}{l}\text { Penghasilan } \\
\text { Orang Tua }\end{array}$} & Tidak Berpenghasilan & 1 \\
\hline & & Rp. 0 - Rp. 900.000 & 3 \\
\hline & & Rp. 1.000 .000 - Rp. 3.000 .000 & 4 \\
\hline & & Rp. 3.000 .000 - Rp. 5.000 .000 & 5 \\
\hline & & $>$ Rp. 5.000 .00 & 2 \\
\hline \multirow{5}{*}{ K03 } & \multirow{5}{*}{ Kelulusan } & $100 \%$ & 5 \\
\hline & & $75 \%-95 \%$ & 4 \\
\hline & & $50 \%-75 \%$ & 3 \\
\hline & & $25 \%-50 \%$ & 2 \\
\hline & & $0 \%$ & 1 \\
\hline \multirow{5}{*}{ K04 } & \multirow{5}{*}{$\begin{array}{l}\text { Penyerapan } \\
\text { Dunia Kerja }\end{array}$} & $>100$ siswa & 5 \\
\hline & & $75-100$ siswa & 4 \\
\hline & & $50-75$ siswa & 3 \\
\hline & & 25 - 50 siswa & 2 \\
\hline & & 0 siswa & 1 \\
\hline \multirow{4}{*}{ K05 } & \multirow{4}{*}{ Sarpras } & Ruang Praktik & 4 \\
\hline & & Alat Peraga & 3 \\
\hline & & Infrastruktur IT & 2 \\
\hline & & Kemudahan Akses & 1 \\
\hline \multirow{18}{*}{ K06 } & \multirow{18}{*}{ Nilai Mapel } & Jika Berminat Jurusan AKL & \\
\hline & & Matematika & 5 \\
\hline & & Bahasa Inggris & 4 \\
\hline & & Prakarya Kewirausahaan & 2 \\
\hline & & Teknologi Informasi dan Komunikasi & 3 \\
\hline & & Seni Gambar & 1 \\
\hline & & Jika Berminat Jurusan OTKP & \\
\hline & & Matematika & 2 \\
\hline & & Bahasa Inggris & 5 \\
\hline & & Prakarya Dan Kewirausahaan & 3 \\
\hline & & Teknologi Informasi dan Komunikasi & 4 \\
\hline & & Seni Gambar & 1 \\
\hline & & Jika Berminat Jurusan BDP & \\
\hline & & Matematika & 3 \\
\hline & & Bahasa Inggris & 2 \\
\hline & & Prakarya Dan Kewirausahaan & 5 \\
\hline & & Teknologi Informasi dan Komunikasi & 4 \\
\hline & & Seni Gambar & 1 \\
\hline
\end{tabular}


Tabel 3. Daftar dan Pembobotan Kriteria (lanjutan)

\begin{tabular}{|c|c|c|c|}
\hline \multirow{12}{*}{ K06 } & \multirow{12}{*}{ Nilai Mapel } & \multicolumn{2}{|l|}{ Jika Berminat Jurusan TKJ } \\
\hline & & Matematika & 3 \\
\hline & & Bahasa Inggris & 4 \\
\hline & & Prakarya Dan Kewirausahaan & 2 \\
\hline & & Teknologi Informasi dan Komunikasi & 5 \\
\hline & & Seni Gambar & 1 \\
\hline & & \multicolumn{2}{|l|}{ Jika Berminat Jurusan MM } \\
\hline & & Matematika & 2 \\
\hline & & Bahasa Inggris & 3 \\
\hline & & Prakarya Dan Kewirausahaan & 1 \\
\hline & & Teknologi Informasi dan Komunikasi & 4 \\
\hline & & Seni Gambar & 5 \\
\hline
\end{tabular}

Berdasarkan pada Tabel 3, terdapat beberapa subkriteria dari masing-masing kriteria dan memiliki nilai bobot masing-masing. Nilai bobot yang ada pada subkriteria tersebut adalah hasil kuisioner kepada beberapa guru dan pimpinan di SMK Ketintang Surabaya.

\section{c. Perhitungan Evaluasi Bobot dan Total Bobot Kriteria}

Alternatif, Kriteria dan Subkriteria telah ditentukan dan telah diberi bobot faktor, Lalu dimulai perhitungan evaluasi bobot (Weighting Value Evaluation) pada alternatif sesuai dengan pemilihan user. Sebelumnya telah diketahui hasil inputan sebagai berikut pada Tabel 4.

Tabel 4. Hasil Input Data User

\begin{tabular}{llccccc}
\hline \multirow{2}{*}{ Kode } & \multirow{2}{*}{ Kriteria } & \multicolumn{5}{c}{ Evaluasi Kriteria $(\boldsymbol{e})$} \\
\cline { 3 - 7 } & & AKL & OTKP & BDP & TKJ & MM \\
\hline K01 & Peminatan & 4 & 3 & 3 & 1 & 1 \\
K02 & Penghasilan Orang Tua & 3 & 3 & 3 & 3 & 3 \\
K03 & Kelulusan & 5 & 4 & 4 & 4 & 1 \\
K04 & Penyerapan Dunia Kerja & 4 & 5 & 3 & 3 & 1 \\
K05 & Sarpras & 3 & 3 & 2 & 3 & 3 \\
K06 & Nilai Mapel & 5 & 4 & 3 & 2 & 1 \\
\hline \multicolumn{2}{c}{ Total } & $\mathbf{2 4}$ & $\mathbf{2 2}$ & $\mathbf{1 8}$ & $\mathbf{1 6}$ & $\mathbf{1 0}$ \\
\hline
\end{tabular}

Dengan perhitungan diatas dapat diketahui nilai dari jumlah total yang diterima untuk masingmasing alternatif. Nilai Evaluasi Kriteria kompetensi keahlian AKL paling tinggi nilainya disbanding dengan kompetensi lainnya dengan total nilai evaluasi kriteria (e) 24. Langkah selanjutnya yaitu menghitung evaluasi pada setiap alternatif sampai semua alternatif dihitung evaluasi bobotnya (Weighting Value Evaluation) pada masing-masing kompetensi keahlian. Perhitungan evaluasi bobot adalah nilai bobot kriteria dikalikan evaluasi kriteria pada Tabel 4 seperti persamaan berikut.

$w v e=v e f \mathrm{x} w f$

\section{Keterangan:}

wve : Weighting Value Evaluation (Evaluasi Nilai Bobot)

vef : Value Of Evaluations Factors (Nilai Evaluasi Faktor)

vwf : Value Of Weighting Factors (Nilai Bobot Faktor) 
Setelah mengetahui evaluasi bobot kriteria maka dilanjutkan perhitungan untuk menghitung total evaluasi bobotnya sehingga menjadi total evaluasi alternatif pada persamaan berikut.

$t e v=w v e_{1}+w v e_{2}+w v e_{3} \ldots . . . w v e_{n}$

Keterangan:

tev : Total Evaluation Value (Nilai Evaluasi Total)

wve 1 : Weighting Value Evaluation-1 (Evaluasi Nilai Bobot ke-1)

$w_{n}$ : Weighting Value Evaluation-n (Evaluasi Nilai Bobot ke-n)

Tabel 5. Evaluasi Alternatif Pertama

\begin{tabular}{clccc}
\hline Kode & \multicolumn{1}{c}{ Kriteria } & $\begin{array}{c}\text { Bobot } \\
(\boldsymbol{w})\end{array}$ & $\begin{array}{c}\text { Evaluasi } \\
(\boldsymbol{e})\end{array}$ & $\begin{array}{c}\text { Bobot Evaluasi } \\
(\boldsymbol{w} * \boldsymbol{e})\end{array}$ \\
\hline K01 & Peminatan & 0,35 & 4 & 1,4 \\
K02 & Penghasilan Orang Tua & 0,15 & 3 & 0,45 \\
K03 & Kelulusan & 0,15 & 5 & 0,75 \\
K04 & Penyerapan Dunia Kerja & 0,1 & 4 & 0,4 \\
K05 & Sarpras & 0,1 & 3 & 0,3 \\
K06 & Nilai Mapel & 0,15 & 5 & 0,75 \\
\hline \multicolumn{2}{r}{ Total } & & $\mathbf{3 , 3}$ \\
\hline
\end{tabular}

Pada evaluasi alternatif pertama Tabel 5, nilai bobot evaluasi Akuntansi dan Keuangan Lembaga adalah 3,3 dimana kriteria peminatan (K01) dan kelulusan (K03) memiliki nilai evaluasi (e) paling tinggi yaitu 5 pada 2 kriteria tersebut.

Tabel 6. Evaluasi Alternatif Kedua

\begin{tabular}{llccc}
\hline \multirow{2}{*}{ Kode } & \multicolumn{1}{c}{ Kriteria } & $\begin{array}{c}\text { Bobot } \\
(\boldsymbol{w})\end{array}$ & $\begin{array}{c}\text { Evaluasi } \\
(\boldsymbol{e})\end{array}$ & $\begin{array}{c}\text { Bobot Evaluasi } \\
(\boldsymbol{w} * \boldsymbol{e})\end{array}$ \\
\hline K01 & Peminatan & 0,35 & 3 & 1,05 \\
K02 & Penghasilan Orang Tua & 0,15 & 3 & 0,45 \\
K03 & Kelulusan & 0,15 & 4 & 0,6 \\
K04 & Penyerapan Dunia Kerja & 0,1 & 5 & 0,5 \\
K05 & Sarpras & 0,1 & 3 & 0,3 \\
K06 & Nilai Mapel & 0,15 & 4 & 0,6 \\
\hline \multicolumn{2}{c}{ Total } \\
\hline
\end{tabular}

Pada evaluasi alternatif kedua Tabel 6, nilai bobot evaluasi Otomatisasi dan Tata Kelola Perkantoran adalah 2,9. Tabel 6 juga memiliki nilai evaluasi $(e)$ yang sering muncul yaitu 3 untuk kriteria peminatan (K01), penghasilan orang tua (K02), dan sarpras (K06) serta nilai paling tinggi yaitu 5 pada kriteria penyerapan dunia kerja (K04).

Tabel 7. Evaluasi Alternatif Ketiga

\begin{tabular}{llccc}
\hline Kode & \multicolumn{1}{c}{ Kriteria } & $\begin{array}{c}\text { Bobot } \\
(\boldsymbol{w})\end{array}$ & $\begin{array}{c}\text { Evaluasi } \\
(\boldsymbol{e})\end{array}$ & $\begin{array}{c}\text { Bobot Evaluasi } \\
(\boldsymbol{w} * \boldsymbol{e})\end{array}$ \\
\hline K01 & Peminatan & 0,35 & 3 & 1,05 \\
K02 & Penghasilan Orang Tua & 0,15 & 3 & 0,45 \\
K03 & Kelulusan & 0,15 & 4 & 0,6 \\
K04 & Penyerapan Dunia Kerja & 0,1 & 3 & 0,3 \\
K05 & Sarpras & 0,1 & 2 & 0,2 \\
K06 & Nilai Mapel & 0,15 & 3 & 0,45 \\
\hline \multicolumn{2}{c}{ Total } \\
\hline
\end{tabular}


Pada evaluasi alternatif ketiga Tabel 7, nilai bobot evaluasi Bisnis Daring dan Pemasaran adalah 2,6 dengan nilai evaluasi (e) yang sering muncul yaitu 3 sebanyak 4 kali dan memiliki nilai terendah yaitu 2 pada kriteria Sarpras (K05).

Tabel 8. Evaluasi Alternatif Keempat

\begin{tabular}{llccc}
\hline Kode & \multicolumn{1}{c}{ Kriteria } & $\begin{array}{c}\text { Bobot } \\
(\boldsymbol{w})\end{array}$ & $\begin{array}{c}\text { Evaluasi } \\
(\boldsymbol{e})\end{array}$ & $\begin{array}{c}\text { Bobot Evaluasi } \\
(\boldsymbol{w} * \boldsymbol{e})\end{array}$ \\
\hline K01 & Peminatan & 0,35 & 1 & 0,35 \\
K02 & Penghasilan Orang Tua & 0,15 & 3 & 0,45 \\
K03 & Kelulusan & 0,15 & 4 & 0,6 \\
K04 & Penyerapan Dunia Kerja & 0,1 & 3 & 0,3 \\
K05 & Sarpras & 0,1 & 3 & 0,3 \\
K06 & Nilai Mapel & 0,15 & 2 & 0,3 \\
\hline \multicolumn{2}{r}{ Total } & & $\mathbf{2}$ \\
\hline
\end{tabular}

Pada evaluasi alternatif keempat Tabel 8, nilai bobot evaluasi Teknik Komputer dan Jaringan adalah 2. Total bobot evaluasi dengan angka bulat pada hasil percobaan progam SPK tersebut. Nilai terendah yang ada pada percobaan ini yaitu pada kriteria Peminatan (K01) dimana calon siswa tidak atau sedikit memilih pernyataan yang mengandung tentang kompetensi keahlian TKJ.

Tabel 9. Evaluasi Alternatif Kelima

\begin{tabular}{llccc}
\hline Kode & \multicolumn{1}{c}{ Kriteria } & $\begin{array}{c}\text { Bobot } \\
(\boldsymbol{w})\end{array}$ & $\begin{array}{c}\text { Evaluasi } \\
(\boldsymbol{e})\end{array}$ & $\begin{array}{c}\text { Bobot Evaluasi } \\
(\boldsymbol{w} * \boldsymbol{e})\end{array}$ \\
\hline K01 & Peminatan & 0,35 & 1 & 0,35 \\
K02 & Penghasilan Orang Tua & 0,15 & 3 & 0,45 \\
K03 & Kelulusan & 0,15 & 1 & 0,15 \\
K04 & Penyerapan Dunia Kerja & 0,1 & 1 & 0,1 \\
K05 & Sarpras & 0,1 & 3 & 0,3 \\
K06 & Nilai Mapel & 0,15 & 1 & 0,15 \\
\hline \multicolumn{2}{r}{ Total } \\
\hline
\end{tabular}

Pada evaluasi alternatif keempat Tabel 9, nilai bobot evaluasi Multimedia adalah 1,35 dimana nilai evaluasi (e) paling kecil ada pada pilihan alternatif ini yang ditunjukan pada kriteria peminatan (K01), kelulusan (K03), penyerapan dunia kerja (K04), dan nilai mapel (K06).

\section{d. Analisis Total Bobot Kriteria}

Proses selanjutnya adalah melakukan perangkingan dari semua total total bobot kriteria masingmasing alternatif agar dapat memilih alternatif terbaik untuk mengambil keputusan.

Tabel 10. Hasil Perhitungan dan Peringkat

\begin{tabular}{lccc}
\hline \multicolumn{1}{c}{ Kriteria } & $\begin{array}{c}\text { Nilai Bobot Evaluasi } \\
(\boldsymbol{w} * \boldsymbol{e})\end{array}$ & $\begin{array}{c}\text { Prosentase } \\
(\boldsymbol{\%})\end{array}$ & Peringkat \\
\hline Akuntansi dan Keuangan Lembaga (AKL) & 3,3 & 22 & 1 \\
Otomatisasi dan Tata Kelola Perkantoran (OTKP) & 2,9 & 19 & 2 \\
Bisnis Daring dan Pemasaran (BDP) & 2,6 & 17 & 3 \\
Teknik Komputer dan Jaringan (TKJ) & 2 & 13 & 4 \\
Multimedia (MM) & 1,35 & 9 & 5 \\
\hline
\end{tabular}

Setelah mengetahui nilai bobot evaluasi masing-masing alternatif, langkah terakhir pada progam SPK adalah mengurutkan nilai bobot evaluasi dari terbesar ke yang terkecil dengan menampilkan 
hasilnya kepada calon siswa. Berdasarkan tabel hasil perhitungan dan peringkat diatas nilai evaluasi masing alternatif yaitu AKL bernilai 3,3; OTKP bernilai 2,9; BDP bernilai 2,6; TKJ bernilai 2; dan MM bernilai 1,35 ;. Hasil diatas telah diurutkan secara otomatis oleh sistem sehingga dapat disimpukan bahwasanya kompetensi keahlian yang dipilih oleh calon siswa adalah Akuntansi dan Keuangan Lembaga dengan nilai 3,3 dan prosentase $22 \%$ dengan memperhatikan beberapa kriteria yang telah ditentukan diantaranya kriteria penghasilan orang tua yang mendapat nilai evaluasi sebesar 0,45. Selanjutnya kriteria Kelulusan pada kompetensi keahlian nilai evaluasi tersebut sebesar 0,75. Kriteria Penyerapan Dunia Kerja di Dunia Industri dengan nilai evaluasi sebesar 0,4. Selanjutnya kriteria Sarana Prasarana penunjang proses pembelajaran dengan nilai evaluasi sebesar 0,3. Dan kriteria Nilai Mata Pelajaran dengan nilai evaluasi sebesar 0,75. Hal ini menunjukkan calon siswa lebih berminat pada kompetensi keahlian AKL dibandingkan kompetensi lainnya yang tersedia.

\section{2 Implementasi MFEP}

Selain perhitungan manual yang berjalan dalam sistem, disertakan pula gambar beberapa menu dari progam SPK dalam penelitian ini seperti halaman login dengan cara calon siswa mendaftar terlebih dahulu, halaman menu utama, halaman peminatan berupa inti progam yang digunakan sebagai pemilihan alternatif terbaik dengan memeperhatikan subkriteria yang dipilih, dan hasil keputusan (summary) dari progam tersebut yang dapat menjadi acuan calon siswa dalam memilih progam keahlian yang tersedia di SMK Ketintang Surabaya. Pada tahap ini menggunakan template bootstrap 4 dengan framework CodeIgniter $(\mathrm{CI})$ dan database aplikasi MySQL berbasis web landing page. framework CodeIgniter (CI) sendiri memiliki struktur pemograman yang terbagi menjadi 3 bagian utama yaitu controller sebagai penghubung anatar model dan view, model sebagai pemanggil data dalam database, dan views sebagai tampilan hasil data yang diproses dari model dan controller.

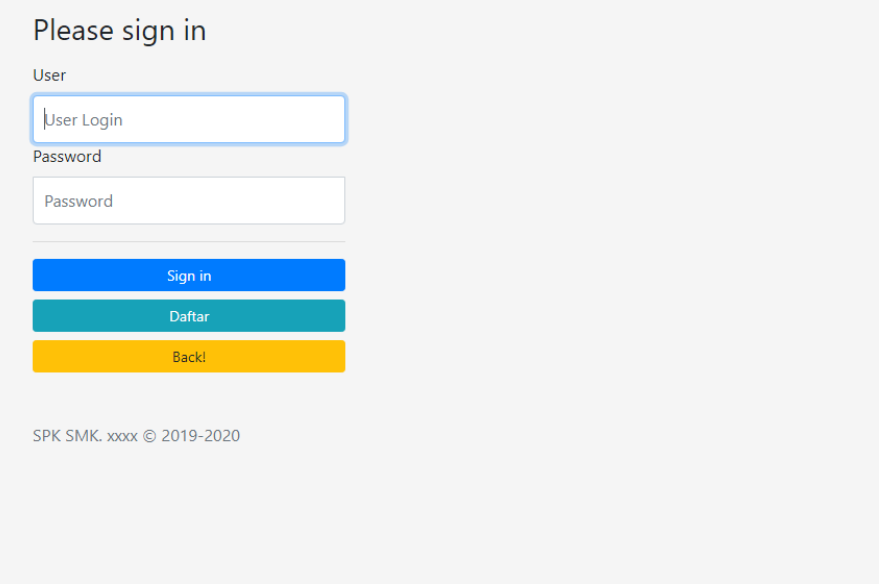

Gambar 1. Form Login

Pada Gambar 1, terdapat 2 textfield untuk memasukkan username dan password. Username dan password hanya bisa didapatkan saat meminta hak askses melalui user admin. Lalu tertera button Sign in untuk masuk kedalam sistem sesuai dengan username sesuai hak akses yang diberikan. Button sign juga sebagai controller untuk melakukan pengecekan ke dalam database progam apakah ada record data yang sesuai dengan yang diisikan di textfield username dan password disertai dengan models sebagai pelaksana dari data yang diinputkan untuk dicek kedalam controller. Setelah melakukan pengecekan data dari primary key level user, sistem akan menampilkan view halaman sesuai dengan 
level user yang telah diverifikasi. Bagi user yang belum memiliki username dan password dapat memilih button Daftar yang akan memunculkan halaman pengisian data user.

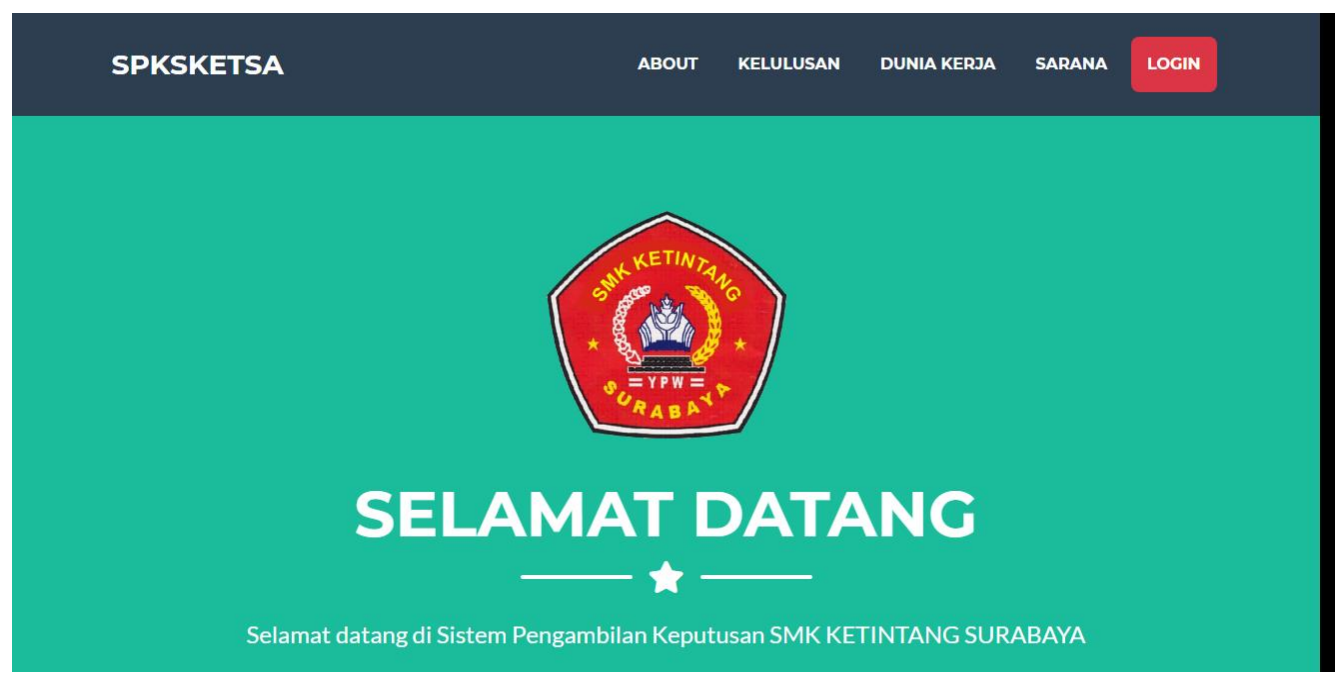

Gambar 2. Halaman Menu Utama

Gambar 2 adalah halaman utama yang terdiri menu login untuk semua user yang memiliki akses didalamnya dan menu mulai untuk memulai progam SPK. Untuk bisa login ke sistem perlu mendapat ijin akses berupa username dan password dari admin terlebih dahulu. Kemudian ada beberapa menu yang ada diatas halaman utama tersebut seperti About, Kelulusan Dunia Kerja, Sarana, dan Login. Selain menu Login, menu lainnya adalah kriteria dari SPK Kompetensi Keahlian yang berpengaruh pada perhitungan pemilihan alternatif kompetensi keahlian. Halaman ini berbasis web landing page dengan beberapa halaman. Pada halaman utama terdapat logo utama dari SMK Ketintang Surabaya dengan header word "Selamat Datang". Terdapat perkenalan pertama dari SPK Kompetensi Keahlian kepada user calon siswa.

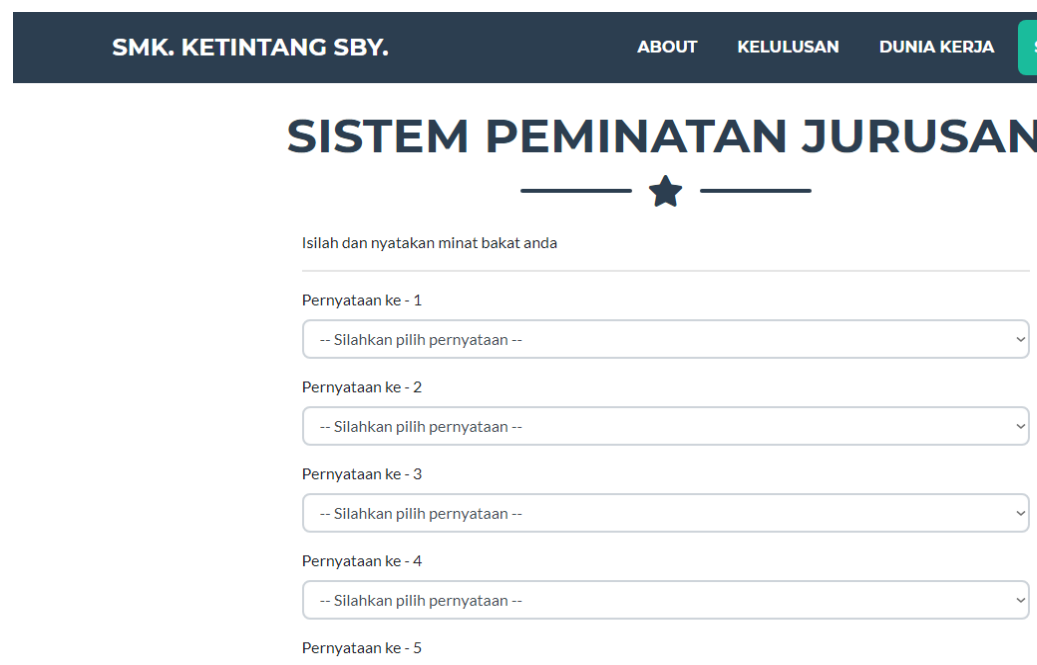

Gambar 3. Halaman Peminatan

Gambar 3 dengan landing page yang terdiri dari beberapa combo box berisi tentang pernyataanpernyataan tentang peminatan jurusan di setiap kompetensi keahlian. User calon siswa dapat memilih pernyataan yang diajukan oleh progam SPK Kompetensi Keahlian sesuai dengan minantnya dengan memilih salah satu dari pernyataan yang muncul di combo box setiap pernyataan. Apabila pernyataan 
terpilih maka pernyataan tersebut akan tampil didalam combo box tersebut. Setelah user calon siswa sudah memilih semua pernyataan maka akan disimpan oleh sistem sebagai variabel untuk menjadi perhitungan mencari alternatif terbaik. Untuk halaman Peminatan ini, data peminatan telah diinputkan oleh user dengan level Waka Kurikulum sehingga user calonsiswa tidak mengisi data melainkan memilih data yanag ada pada combo box tersebut. Data ditarik dengan model peminatan pada controller akun Wakakur sehingga dapat menampilakn view peminatan sesuai dengan data yang sudah ada. Lalu ketika user calon siswa memilih salah satu data peminatan diatas, maka model peminatan akan menyimpan hasil pemilihan data tersebut ke dalam database untuk nantinya digunakan sebagai perhitungan pada halaman kesimpulan (summary).

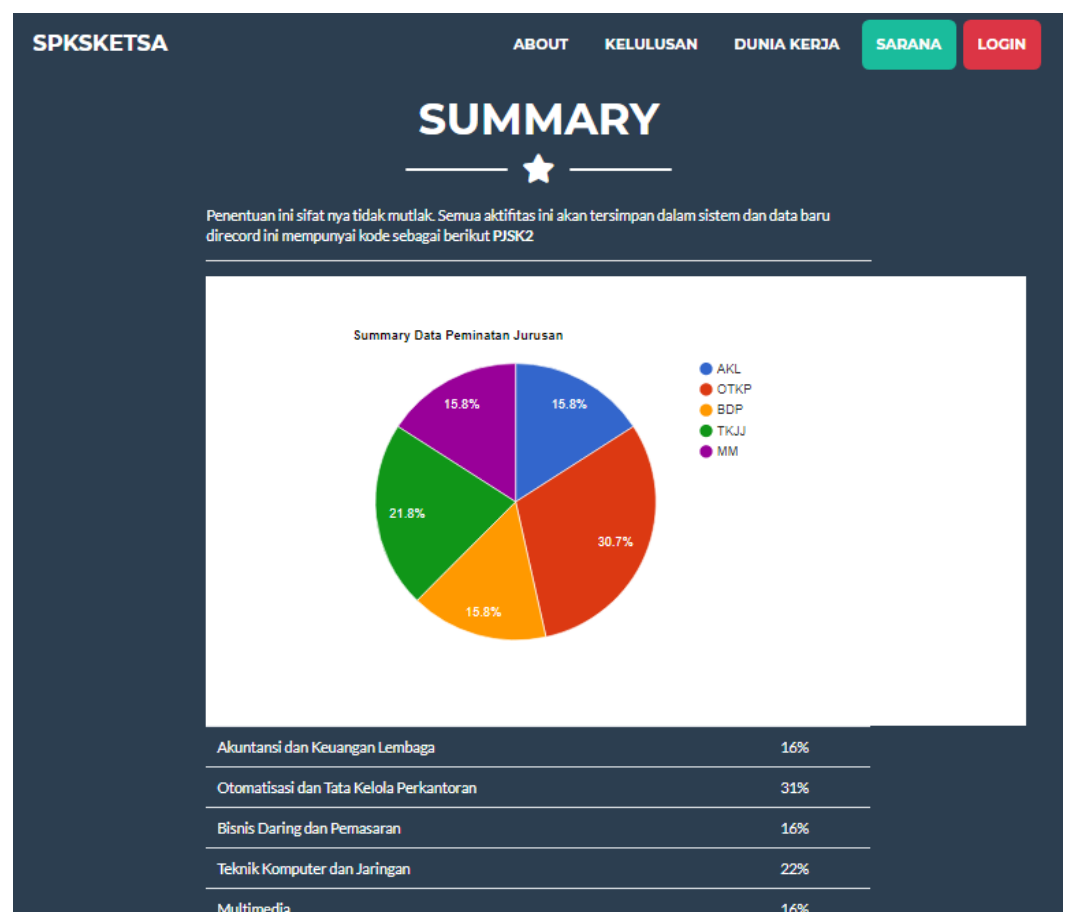

Gambar 4. Halaman Hasil Keputusan (Summary)

Kemudian sistem akan menampilkan Gambar 4 yang merupakan hasil dari keputusan yang dibuat oleh user calon siswa. Pada halaman tersebut akan tampil alternatif-alternatif keputusan yaitu berupa pilihan kompetensi keahlian yang dipilih sebelumnya. Prosentase adalah hasil perhitungan dari beberapa kriteria yang dipilih pada halaman sebelumnya dan ditampilkan berupa grafik pie sesuai dengan prosentasenya. Lalu terdapat pesan kepada user calon siswa berupa pesan pengingat bahwasanya SPK tersebut hanya membantu user calon siswa dalam memilih kompetensi keahlian pada jenjang SMK sesuai dengan bakat dan minatnya. Pilihan kompetensi keahlian pada saat pendaftaran diserahkan langsung kepada calon siswa. Selain itu terdapat juga kode hasil SPK yang dilakukan dan disimpan di database sistem dengan kode "PJSKXX" dimana nantinya user calon siswa dapat melihat history pemilihan yang pernah dilakukan sebelumnya. Setelah semua data dipilih oleh calon siswa, maka data akan dipanggil kembali pada halaman ini dengan model summary.php dengan controller halaman utama. Pada halaman utaman juga sistem melakukan beberapa fuction untuk melakukan perhitungan data yang telah ditarik tersebut kedalam prosentase penunjang keputusan. Setelah terbentuk data prosentase, data diteruskan model summary.php agar dapat tersimpan di database dan mendapatkan tampilan view pada halaman utama bagian halaman kesimpulan (Summary) yang terdiri dari view diagram pie beserta data prosentasenya dan kode SPK dari perhitungan data yang telah disimpan oleh model summary.php dengan susunan jenis kode unik. 


\section{Kesimpulan}

Simpulan dari peneletian ini adalah Sistem Penunjang Keputusan (SPK) Pemilihan Kompetensi Keahlian untuk calon siswa SMK dapat digunakan sebagai alat untuk mempermudah pemilihan kompetensi keahlian sesuai dengan minat atau kesukaan dari calon siswa dengan menggunakan metode Multi Factor Evaluation Process (MFEP) yang memberi nilai pada subkriteria paling mempengaruhi alternatif (Ramadhan dan Yusfrizal, 2019; Aningke, dkk., 2018). Berdasarkan perhitungan metode tersebut pilihan kompetensi keahlian adalah pilihan terbaik dari total bobot evaluasi dari setiap perhitungan alternatif dimana total bobot evaluasi tertinggi adalah 3,3 untuk alternatif kompetensi keahlian Akuntansi dan Keuangan Lembaga.

Desain sistem yang digunakan adalah metode Waterfall dengan tahapan Planning, Analisis, Design, dan Implementasi. Tahap Planning dilakukan dengan melakukan proses pengumpulan data dan studi literature pendukung penelitian. Lalu tahap Analisis dengan pengamatan terhadap alur proses bisnis yang terjadi. Tahap Design dengan membuat desain progam. Pada tahap Implementasi menampilkan halaman-halaman yang ada pada progam SPK Kompetensi Keahlian.

Saran yang dapat diberikan untuk penelitian ini adalah semakin banyak kriteria yang dibuat untuk menentukan maka keputusan yang dihasilkan akan semakin tepat dan efektif pada peminatan calon siswa. Kriteria-kriteria yang dipilih perlu diambil dari faktor-faktor yang mempengaruhi dalam pemilihan alternatif sehingga hasil dari SPK dapat sesuai dengan harapan dari calon siswa sebagai pengguna dan pihak sekolah sebagai pelayanan jasa pendidikan.

Metode MFEP juga dapat dikembangan dan dikombinasikan dengan metode lain untuk saling melengkapi agar keputusan menjadi lebih baik lagi. Dalam metode MFEP, kriteria diberikan bobot dan dijadikan mejadi kategori subkriteria yang diberikan bobot pula dimana perhitungan tanpa melakukan normalisasi terhadap total bobot yang ada sehingga keakuratan dalam perhitungan kurang maksimal. Melakukan pengembangan progam agar bisa saling terintegrasi dengan sistem pendaftaran siswa baru dan progam-progam lainnya yang berkaitan sehingga dapat menunjang kegiatan operasional sekolah pada saat penerimaan peserta didik baru.

\section{Ucapan Terima Kasih}

Ucapan terima kasih kepada Bapak Aryo Nugroho, S.Kom., MT. selaku Dekan Fakultas Ilmu Komputer Universitas Narotama, Ibu Immah Inayati, S.Kom., M.Kom., MBA selaku Ketua Progam Studi Sistem Informasi, seluruh bapak ibu dosen Fakultas Ilmu Komputer Universitas Narotama atas ilmu dan arahan yang telah diberikan.

Ucapan terima kasih kepada Kepala Sekolah, Wakil Kepala Sekolah, Ketua Kompetensi Keahlian beserta staff, guru, dan pegawai SMK Ketintang Surabaya yang telah mengijinkan dan membantu untuk melakukan observasi data. Semoga makalah tersebut dapat menjadikan manfaat bagi kita semua. Amin.

\section{Daftar Pustaka}

Aningke, T., Pradana, Y., Facharaini, N. I, dan Gukguk, M. R.. (2018). Penerapan algoritma MFEP dalam merekomendasikan mode hijab terbaik dikalangan remaja. Jurnal Informatika, Vol. 18, No. 1, hal. 1-8.

JawaPos.com. [online]: https://www.jawapos.com/pendidikan/17/06/2017/banyak-siswa-terpaksa tinggal-kelas/ (Diakses: 4 Juli 2019).

Kementrian Pendidikan dan Kebudayaan Direktorat Jenderal Pendidikan Dasar Dan Menengah. (2018). Peraturan Direktur Jenderal Pendidikan Dasar dan Menengah Kementrian Pendidikan dan Kebudayaan Tentang Spektrum Keahlian Sekolah Menengah Kejuruan (SMK) / Madrasah Aliyah Kejuruan (MAK). Indonesia: Kemendikbud RI. 
Manik, A. R. S., Nurhadiyono, B., dan Rahayu, Y. (2015). Implementasi metode weighted product (wp) dalam sistem pendukung keputusan untuk menyeleksi penerima beras masyarakat miskin (raskin). Techno.COM, Vol. 14, No. 2, hal. 109-114.

Muchlis, M., Christian A. dan Sari, M.P. (2019) Kuesioner online sebagai media feedback terhadap pelayanan akademik pada STMIK Prabumulih. Eksplora Informatika, Vol. 8, No. 2, hal. 149-157.

Primadasa, Y. dan Amalia, V. (2018) Penerapan metode multi factor evaluation process untuk pemilihan tanaman pangan di Kabupaten Musi Rawas. Sisfo, Vol. 7, No. 1, hal. 47-58.

Ramadhan, M. H. dan Yusfrizal. (2019). Analisis dan penerapan metode multifactor evaluation process (mfep) dalam menentukan bibit tanaman buncis yang layak untuk dibudidayakan. Jurnal Sistem Informasi Kaputama (JSIK), Vol. 3, No. 1, hal. 18-26.

Wahyuni, A. (2017). Sistem pendukung keputusan pemilihan jurusan di Sekolah Menengah Kejuruan 1 Cengkareng Jakarta. Jurnal Interkom, Vol. 12, No. 3, hal. 4-13.

Widjaja, A. dan Mujito. (2017). Implementation of the algorithm of multi-factor evalution process (MFEP) for the election of the members of the investigator at Bareskrim Police. International Journal of Pure and Applied Mathematics, Vol. 116, No. 24, hal. 381-394.

Wuragil, A., Yaqin A., dan Perbawa, D. S. (2014). Sistem pendukung keputusan sebagai alternatif pemilihan jurusan calon peserta didik baru (studi kasus: SMK Muhammadiyah Magelang). Seminar Nasional Teknologi Informasi dan Multimedia SMIK AMIKOM Yogyakarta, Vol. 2, No. 1, hal. 7-12. 